\title{
METODE PARTICLE SWARM OPTIMIZATION UNTUK OPTIMASI PORTOFOLIO
}

\author{
Rini Widia Putri Z \\ Program Studi Informatika, Universitas Indraprasta PGRI \\ r.widia.putri@gmail.com
}

\begin{abstract}
Abstrak
Saham merupakan salah satu aset keuangan yang populer diinvestasikan dewasa ini. Walau pergerakan harga saham tidak tetap namun dapat diprediksi untuk jangka waktu tertentu, sehingga keuntungan yang akan diperolehpun dapat diperkirakan. Saham-saham yang dimiliki dapat disusun sedemikian rupa sehingga dapat memperoleh keuntungan paling maksimal dengan resiko paling minimal melalui portofolio. Portofolio juga dapat disusun dengan berbagai kendala, salah satunya kendala sector capitalization.Portofolio dengan kendala ini tidak menghasilakan proporsi masing-masing saham, tetapi proporsi setiap sektor yang didalamnya tergabung berbagai saham. Pada pelaksanaannya, investor akan tertarik menginvestasikan modal mereka pada saham-saham yang memiliki nilai tinggi di pasar modal. Dengan memilih berinvestasi diberbagai sektor, investor dapat meminimalkan risiko seandainya satu sektor yang dipilih ternyata memperoleh kerugian. Optimasi dengan kendala ini merupakan masalah optimasi tak linear dengan variabel bilangan bulat dan bilangan real, maka dibantu dengan metode Particle Swarm Optimization. Hasil optimasi yang diperoleh pada artikel ini adalah bobot lima sektor saham-saham LQ45 secara berurut yaitu $0.353 ; 0.2465 ; 0.222 ; 0.1164$; 0,0955 dengan ririko sebesar 0.0030 .
\end{abstract}

Kata Kunci : Portofolio, Particle Swarm Optimization

\begin{abstract}
Stock is one of financial assets popularly invested in the present time. In spite of its unstable movement, stock price can be predicted for certain period of time to estimate the profit that will be made. The owned stocks can be systematically arranged to produce a maximum profit with minimal risks through portfolio. Portfolio can be arranged by imposing various constraints, such as sector capitalization. With this constraint, portfolio does not create a proportion for each stock, but for every sector containing various stocks. If implemented, the investor may be interested in investing their capital into the stocks that have the high value in the capital market. By investing in various stocks, investors can minimize the risks provided one of the chosen sectors suffers loss. Optimization with this constraint is a non-linear optimization problem with integer and real numbers with the help of Particle Swarm Optimization method. The optimization results in this article show the consecutive weight of five sectors of LQ45 stocks are 0,353; 0,2465; 0,222; 0,1164; 0,0955 with the risk of 0,0030.
\end{abstract}

Keywords: Portfolio, Particle Swarm Optimization

\section{PENDAHULUAN}

Salah satu kajian menarik di bidang keuangan adalah mengenai portofolio. Portofolio merupakan pengelompokan aset keuangan berupa saham atau obligasi yang diperdagangkan di bursa oleh investor dan dikelola oleh para profesional. Aset keuangan dalam portofolio disusun dengan tujuan untuk memperoleh portofolio yang efisien yaitu portofolio yang bisa memberikan return yang maksimal dengan risiko tertentu.

Seorang investor dapat memilih satu dari sekian banyak pilihan kumpulan portofolio efisien berupa portofolio optimal sesuai pilihan terhadap return dan risiko. Portofolio yang optimal dapat dianalisis berdasarkan karakteristik setiap aset yang dimasukkan dalam portofolio. 
Karakteristik utama yang dipertimbangkan adalah tingkat keuntungan dan risiko masing-masing aset.Secara sederhana dapat dilakukan dengan mengalokasikan proporsi yang kecil untuk aset yang memiliki risiko tinggi dan memberikan alokasi proporsi yang besar untuk aset yang memiliki risiko yang rendah.

Teori pendukung analisis portofolio optimal diperkenalkan oleh Markowitz dalam [1] yang membangun sebuah model portofolio untuk menghitung tingkat keuntungan dengan mean dari return dan menghitung risiko dengan variansi dari portofolio. Risiko dinyatakan sebagai ukuran perbedaan hasil keuntungan yang diperoleh dengan hasil keuntungan yang diharapkan (expected return).

Dalam pelaksanaannya, portofolio yang optimal diperoleh dengan menentukan bobot masing-masing saham agar memenuhi return dan risiko yang diinginkan.

Peneliti terdahulu telah banyak memanfaatkan model portofolio Markowitz untuk mengoptimasi portofolio. Referensi [2] menggunakan model ini untuk menyelesaikan masalah portofolio dengan kendala buy-in threshold dan roundlot menggunakan DIRECT yang memanfaatkan metode Quasi-Newton. Referensi [7] menggunakan model ini untuk menyelesaikan masalah portofolio dengan kendala minimum transaction lots, cardinality, dan sector capitalization menggunakan metode Genetic Algorithm.

Penelitian yang dilakukan penulis adalah menggunakan metode Particle Swarm Optimization (PSO) untuk menyelesaikan masalah optimasi portofolio dengan kendala sector capitalization.

Kendala sector capitalization membahas tentang kecenderungan investor untuk berinvestasi pada sektor yang memiliki nilai lebih tinggi pada pasar modal [7]. Modal pada sektor lebih dipertimbangkan sebagai kendala untuk pemilihan saham daripada kelayakan dan keamanan.

Untuk dapat meminimalkan risiko dalam berinvestasi, investor dapat melakukan investasi pada berbagai sektor sehingga risiko kerugian pada satu sektor dapat ditutupi dengan keuntungan pada sektor yang lainnya.Dalam satu portofolio, investasi itu sendiri dapat dilakukan pada beberapa sektor yang berbeda-beda.

Hubungannya dengan pasar modal adalah bobot setiap saham terpilih pada sektor yang berbeda akan dipengaruhi modal sektor, maksudnya sektor yang memiliki banyak modal seharusnya punya proporsi yang lebih utama untuk dipilih. Oleh sebab itu, pembatasan dihilangkan jika tidak ada saham yang terpilih dari sebuah sektor.

Metode Particle Swarm Optimization (PSO) pertama kali dikenalkan oleh Dr. Eberhart dan Dr. Kennedy pada tahun 1995 dalam sebuah konferensi jaringan syaraf di Perth, Australia [6]. Metode ini berupa sebuah optimisasi stokastik terhadap suatu populasi.Dalam sains komputasi, PSO adalah metode komputasi yang mengoptimisasi sebuah masalah dengan mencoba meningkatkan calon solusi dari masalah tersebut secara berulang-ulang dengan memperhatikan ukuran dari kualitas yang diberikan.

Menurut [4] pada mulanya PSO terinspirasi dari perilaku sebuah kawanan serangga, seperti semut, rayap, lebah, atau burung. Misalkan sekelompok burung sedang mencari makanan secara acak di suatu daerah. Hanya ada satu potongan makanan di daerah tersebut yang sedang dicari. Akan tetapi burung-burung tersebut tidak mengetahui dimana makanan tersebut berada tetapi tahu seberapa jauh makanan itu berada. Salah satu cara yang efektif untuk memperoleh makanan adalah dengan mengikuti burung yang berada paling dekat dengan makanan tersebut. 


\section{METODE PENELITIAN}

Dalam menyelesaikan optimasi portofolio ini, peneliti menggunakan metode Particle Swarm Optimization. Adapun dalam pelaksanaannya penulis melalui beberapa tahapan :

1. Menyusun model matematika untuk optimisasi portofolio dengan kendala sector capitalization.

2. Memodifikasi algoritma PSO sesuai kebutuhan data.

3. Uji metode PSO.

4. Mengambil dan data saham LQ45.

5. Mengolah data saham. Pertama, data saham yang diperoleh dihitung mean returnnya kemudian dihitung variansi dan kovariansi sahamnya.

6. Menyesuaikan program untuk menyelesaikan masalah sector capitalization.

7. Menjalankan program untuk memperoleh hasil yang paling optimal dengan bantuan algoritma PSO.

\section{HASIL DAN PEMBAHASAN}

Misalkan suatu portofolio terdiri dari $n$ saham dengan bobot masing - masing $y_{1}, y_{2}, y_{3}, \ldots, y_{n}$ memenuhi,

$$
y_{1}+y_{2}+y_{3}+\cdots+y_{n}=1
$$

Misalkan $r_{i j}$ menyatakan return saham $i$ pada periode $j$, dengan $i=1,2, \ldots, n$ dan $j=$ $1,2, . ., m$ maka mean return $\bar{r}_{i}$ untuk setiap saham $i$ adalah

$$
\bar{r}_{i}=\frac{\sum_{j=1}^{m} r_{i j}}{m}
$$

Misalkan seorang investor ingin menyusun portofolio yang terdiri dari $n$ saham dengan harapan memperoleh risiko sekecil mungkin, artinya menemukan nilai $y_{1}, y_{2}, y_{3}, \ldots, y_{n}$ dengan meminimumkan fungsi risiko $y^{T} Q y=V$ dengan $Q$ adalah

$$
Q=\left(\begin{array}{crll}
\sigma_{11} & \sigma_{12} & \ldots & \sigma_{1 n} \\
\sigma_{12} & \sigma_{22} & \ldots & \sigma_{2 n} \\
\vdots & \vdots & \ddots & \vdots \\
\sigma_{1 n} & \sigma_{2 n} & \ldots & \sigma_{n n}
\end{array}\right),
$$

sebuah matriks variansi-kovariansi. Secara matematis masalah ini dapat ditulis : Meminimumkan $\quad V=y^{T} Q y$ dengan kendala $e^{T} y=1$. Selanjutnya jika diberi target return saham sebesar $R_{p}$, masalah menjadi :

Meminimumkan $\mathrm{V}=\mathrm{y}^{\mathrm{T}} \mathrm{Qy}$ dengan kendala $e^{T} y=1$ dan $r^{T} y=R_{p}$,

dapat diselesaikan dengan metode Langrange Multiplier dengan mengubah menjadi masalah tanpa kendala [3].

Kendala sector capitalization membahas tentang kecenderungan investor untuk berinvestasi pada sektor yang memiliki nilai lebih tinggi pada pasar modal. Modal pada sektor lebih dipertimbangkan sebagai kendala untuk pemilihan saham daripada kelayakan dan keamanan.Untuk dapat meminimalkan risiko dalam berinvestasi, investor dapat melakukan investasi pada berbagai sektor sehingga risiko kerugian pada satu sektor dapat ditutupi dengan keuntungan pada sektor yang lainnya.

Untuk menyelesaikan masalah ini,sahamsaham dikelompokkan berdasarkan sektornya, sektor 1 harus memiliki modal yang lebih dari sektor 2 dan ada beberapa saham di portofolio berasal dari kedua sektor ini, maka total bobot saham dari sektor 1 harus lebih banyak dari pada total bobot saham dari sektor 2, tetapi jika tak ada saham yang berasal dari saham 1 maka pembatasan dihapuskan.

Masalah meminimumkan risiko dengan return sebesar $R_{p}$ dengan kendala sector capitalization adalah

$$
\operatorname{Min} V=y^{T} Q y
$$

$$
\text { kendala } \quad r^{T} y=R_{p} \quad e^{T} y=1
$$

$$
\begin{gathered}
\sum_{i_{s}} y_{i_{s}} \geq \sum_{i_{s^{\prime}}} y_{i_{s^{\prime}}} \quad \forall w_{s}, w_{s^{\prime}} \neq 0 ; s, s^{\prime} \\
\in\{1,2, \ldots . S\} s<s^{\prime}
\end{gathered}
$$


Dimana

$$
\begin{aligned}
& w_{s}=\left\{\begin{array}{c}
1 \text { jika } \sum_{i_{s}} z_{i}>0 \\
0 \text { jika } \sum_{i_{s}} z_{i}=0
\end{array}\right. \\
& i_{s}, i_{s^{\prime}} \in\{1,2, \ldots, N\} .
\end{aligned}
$$

Keterangan :

$$
\begin{aligned}
z_{i}=\quad & \text { variabel biner yang bernilai } 1 \text { jika } \\
& \text { setiap saham } i \text { terpilih dan benilai } \\
& 0 \text { jika tidak. } \\
w_{s}= & \text { variabel biner yang bernilai } 1 \text { jika } \\
& \text { paling sedikit } 1 \text { saham pada sector } \\
& s \text { terpilih dan } 0 \text { jika tidak. }
\end{aligned}
$$

Jika tidak ada saham terpilih pada sektor $s$ maka $z_{i}=0$ dan $w_{s}=0$. Tetapi jika terdapat satu saham pada sektor $s$ terpilih, maka $w_{s}$ $=1$.

Kendala sector capitalization dibuat menjadi sebuah kendala yang harus dipenuhi yaitu:

$\sum_{\mathrm{j}=1}^{\mathrm{n}_{1}} \mathrm{y}_{1 \mathrm{j}}-\sum_{\mathrm{j}=1}^{\mathrm{n}_{2}} \mathrm{y}_{2 \mathrm{j}}>0$

$\sum_{j=1}^{n_{2}} y_{2 j}-\sum_{j=1}^{n_{3}} y_{3 j}>0, \ldots d s t$,

$\operatorname{dimanan}_{i}=$ jumlah saham pada tiap-tiap sektor yang terpilih masuk portofolio untuk $i=1,2, . . s$.

Metode Particle Swarm Optimization (PSO) adalah metode komputasi yang mengoptimisasi sebuah masalah dengan mencoba meningkatkan calon solusi dari masalah tersebut secara berulang-ulang dengan memperhatikan ukuran dari kualitas yang diberikan. Pada mulanya PSO terinspirasi dari perilaku sebuah kawanan serangga, seperti semut, rayap, lebah, atau burung. Misalkan sekelompok burung sedang mencari makanan secara acak di suatu daerah. Hanya ada satu potongan makanan di daerah tersebut yang sedang dicari. Akan tetapi burung-burung tersebut tidak mengetahui dimana makanan tersebut berada tetapi tahu seberapa jauh makanan itu berada. Salah satu cara yang efektif untuk memperoleh makanan adalah dengan mengikuti burung yang berada paling dekat dengan makanan tersebut.

Menurut [5] PSO mengoptimisasi sebuah masalah dengan menyiapkan suatu populasi calon solusi untuk masalah yang disebut sebagai partikel-partikel dan memindahkan partikel-partikel tersebut melalui ruang pencarian yang ada dengan mengikuti partikel-partikel optimum yang sedang berjalan sesuai posisi partikel dan kecepatannya. Semua partikel-partikel mempunyai nilai kecocokan (fitness value) yang dievaluasi dengan fungsi kecocokan (fitness function) yang akan dioptimisasi dan mempunyai kecepatan-kecepatan yang langsung mengarah kepada pergerakan partikel-partikel. Selanjutnya partikelpartikel bergerak melalui ruang masalah (space problem) dengan mengikuti partikel-partikel optimum yang sedang berjalan.

Metode PSO diinisialisasi dengan sekelompok partikel acak kemudian mencari solusi optimal dengan memperbaharui generasi-generasinya.Pada setiap iterasi, tiap-tiap partikel diperbaharui dengan mengikuti dua nilai "terbaik". Yang pertama adalah solusi terbaik (fitness) yang telah dicapai oleh partikel-partikel. Nilai ini kemudian disimpan dan disebut sebagai pbest. Terbaik kedua yang diikuti oleh PSO adalah nilai terbaik yang diperoleh sebarang partikel di dalam populasi.Nilai terbaik ini adalah terbaik globaldan disebut gbest. Setelah menemukan dua nilai terbaik, partikel akan memperbaharui kecepatan dan posisinya sebagai berikut :

$$
\begin{aligned}
v_{k+1}^{i}= & v_{k}^{i}+c_{1} r_{1}\left(p_{k}^{i}-x_{k}^{i}\right)+ \\
& c_{2} r_{2}\left(p_{k}^{g}-x_{k}^{i}\right) \\
x_{k+1}^{i}= & x_{k}^{i}+v_{k+1}^{i} .
\end{aligned}
$$




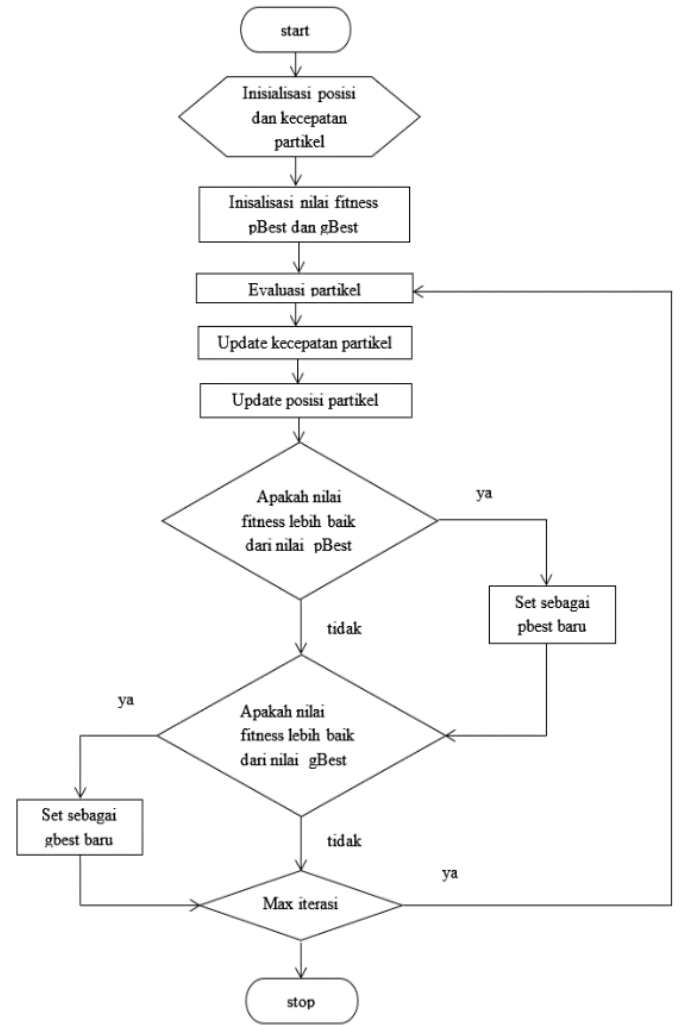

Gambar 1.Flow chart PSO

Adapun algoritma Particle Swarm Optimization sebagai berikut,

1. Inisialisasi sekumpulan partikel $\left(x_{k}^{i}\right)$ secara random (setiap partikel merepresentasikan solusi yang mungkin untuk masalah optimasi).

2. Inisialisasi kecepatan dari setiap partikel $\left(v_{k}^{i}\right)$ dengan asumsi bahwa kecepatan awal partikel $=0$.

3. Evaluasi fungsi tujuan $\left(f_{k}^{i}\right)$.

4. Menentukan posisi terbaik masingmasing partikel untuk setiap iterasi $\left(p_{k}^{i}\right)$ dengan ketentuan jika $f_{k}^{i} \leq$ $f_{\text {best }}^{i}$ maka $f_{\text {best }}^{i}=f_{k}^{i}, p_{k}^{i}=x_{k}^{i}$.

5. Menentukan posisi terbaik untuk setiap populasi $\left(p_{k}^{g}\right)$ dengan ketentuan jika $f_{k}^{i} \leq f_{\text {best }}^{g}$ maka $f_{\text {best }}^{g}=f_{k}^{i}, p_{k}^{g}=x_{k}^{i}$.

6. Memperbaharui posisi dan kecepatan partikel.

7. Pemberhentian iterasi jika telah mencapai nilai optimum atau mencapai iterasi maksimum.
Untuk memudahkan pembahasan, algoritma PSO biasa diberi nama PSO tipe1. Selanjutnya PSO tipe 2 dan tipe 3 adalah sebagai berikut :

1. PSO tipe 2 yaitu Constant inertia weight $\left(\mathrm{w}_{\mathrm{k}}\right)$

Modifikasi terjadi saat update kecepatan :

$$
\begin{aligned}
& v_{k+1}^{i}=w_{k} v_{k}^{i}+c_{1} r_{1}\left(p_{k}^{i}-x_{k}^{i}\right)+ \\
& c_{2} r_{2}\left(p_{k}^{g}-x_{k}^{i}\right) \\
& \text { dengan } \\
& w_{k}=w_{\text {maks }} \cdot \frac{\left(w_{\text {maks }}-w_{\min }\right)}{\text { iterasi maksimum }} \text {. iterasi } \\
& \text { dengan pemilihan } w_{\text {maks }}=0.9 \text { dan } \\
& w_{\text {min }}=0.1
\end{aligned}
$$

2. PSO tipe 3 yaitu Linear Inertia Reduction

Modifikasi terjadi saat updatekecepatan :

$$
\begin{gathered}
v_{k+1}^{i}=w_{k} v_{k}^{i}+c_{1} r_{1}\left(p_{k}^{i}-x_{k}^{i}\right)+ \\
c_{2} r_{2}\left(p_{k}^{g}-x_{k}^{i}\right) \\
w_{k+1}=\alpha w_{k}, 0<\alpha<1
\end{gathered}
$$

Pada uji metode PSO ini digunakan 3 variasi PSO yaitu PSO tipe1, PSO tipe 2, dan PSO tipe 3.Ketiga variasi tersebut digunakan untuk menghitung nilai minimum beberapa fungsi, yaitu :

\section{Fungsi Sphere}

$$
f(\mathrm{x})=\sum_{\mathrm{i}=1}^{\mathrm{D}} \mathrm{x}_{\mathrm{i}}^{2}
$$

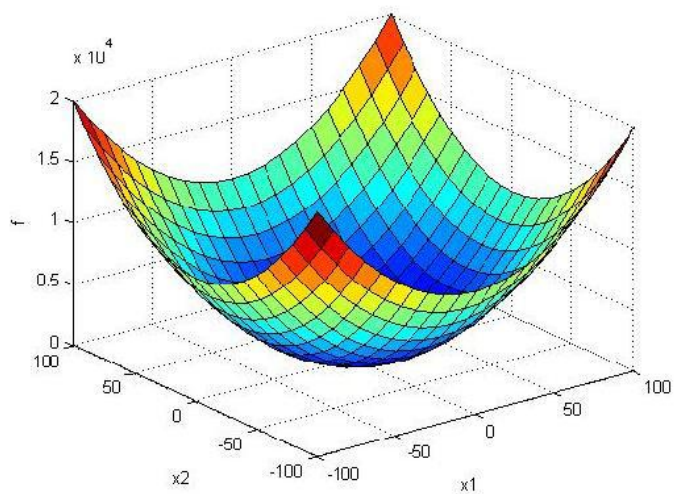

Gambar 2. Ilustrasi Fungsi Sphere 
Fungsi ini dievaluasi pada daerah $100 \leq x_{j} \leq 100, \quad \mathrm{j}=1,2, \ldots, \mathrm{D}$ yang mempunyai nilai minimum $\mathrm{f}(0,0, \ldots, 0)=0$. Adapun input data yang digunakan untuk menghitung nilai fungsi ini menggunakan PSO adalah $\mathrm{D}=10$ dan jumlah partikel = 25. Diperoleh hasil terbaik sebagai berikut:

\section{Tabel 1. Fungsi Sphere}

\begin{tabular}{|c|c|c|c|}
\hline No & PSO & & \\
\hline \multirow{3}{*}{1} & & $f(x)$ & $3.8824 \mathrm{e}-016$ \\
\hline & Tipe 1 & waktu & 21.870906 \\
\hline & & generasi & 1043 \\
\hline \multirow{3}{*}{2} & & $f(x)$ & $4.8811 \mathrm{e}-016$ \\
\hline & Tipe 2 & waktu & 12.530531 \\
\hline & & generasi & 645 \\
\hline \multirow{3}{*}{3} & & $f(x)$ & $3.1714 \mathrm{e}-016$ \\
\hline & Tipe 2 & waktu & 1.957926 \\
\hline & & generasi & 93 \\
\hline
\end{tabular}

\section{Fungsi Hyper-ellipsoid}

$$
f(x)=\sum_{i=1}^{D} 2^{i} x_{i}^{2}
$$

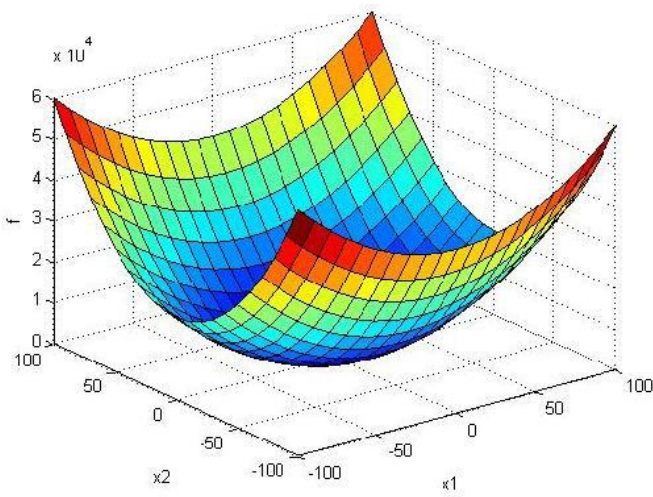

\section{Gambar3.Ilustrasi Fungsi Hyper-ellipsoid}

Fungsi ini dievaluasi pada daerah $100 \leq x_{j} \leq 100, \quad \mathrm{j}=1,2, \ldots, \mathrm{D}$ yang mempunyai nilai minimum $\mathrm{f}(0,0, \ldots, 0)=0$. Adapun input yang digunakan untuk menghitung nilai fungsi ini menggunakan PSO adalah $\mathrm{D}=10$ dan jumlah partikel $=$ 25. Diperoleh hasil sebagai berikut :
Tabel 2. Fungsi Hyper-ellipsoid

\begin{tabular}{cclc}
\hline No & PSO & & \\
\hline \multirow{2}{*}{1} & & $\mathrm{f}(\mathrm{x})$ & $2.27 \mathrm{e}-009$ \\
& \multirow{2}{*}{ Tipe 1 } & waktu & 54.516274 \\
& & generasi & 968 \\
\hline \multirow{2}{*}{2} & \multirow{2}{*}{ Tipe 2 } & $\mathrm{f}(\mathrm{x})$ & $2.01 \mathrm{e}-012$ \\
& & waktu & 37.072827 \\
& & generasi & 648 \\
\hline \multirow{2}{*}{3} & \multirow{2}{*}{ Tipe 2 } & waktu & $1.16 \mathrm{e}-013$ \\
& & generasi & 4.162239 \\
& & & 78 \\
\hline
\end{tabular}

\section{Fungsi Schwefel}

$$
\mathrm{f}(\mathrm{x})=-\frac{1}{\mathrm{D}} \sum_{\mathrm{i}=1}^{\mathrm{D}} \mathrm{x}_{\mathrm{i}} \sin \left(\mathrm{g} \sqrt{\left|\mathrm{x}_{\mathrm{i}}\right|}\right)
$$

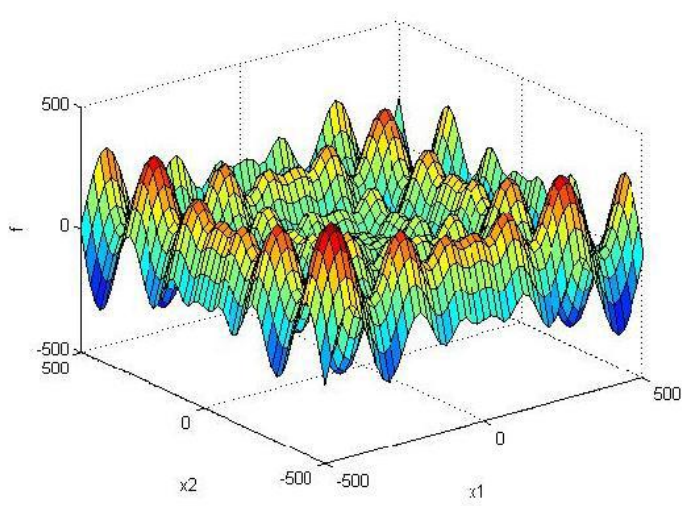

Gambar 4. Ilustrasi Fungsi Schwefel

Fungsi ini dievaluasi pada daerah $-500 \leq x_{j} \leq 500, j=1,2, \ldots, D$ yang mempunyai nilai minimum $\mathrm{f}(420.9687, \ldots, 420.9687)=-418.9831$. Adapun input yang digunakan untuk menghitung nilai fungsi ini menggunakan PSO adalah $\mathrm{D}=10$ dan jumlah partikel $=25$. Diperoleh hasil sebagai berikut :

\section{Tabel 3. Fungsi Schwefel}

\begin{tabular}{cc|lc}
\hline No & PSO & & \\
\hline \multirow{2}{*}{1} & \multirow{2}{*}{ Tipe 1 } & $\mathrm{f}(\mathrm{x})$ & -419.655 \\
& & waktu & 0.116086 \\
& generasi & 1000 \\
\hline \multirow{3}{*}{2} & \multirow{3}{*}{ Tipe 2 } & $\mathrm{f}(\mathrm{x})$ & -419.093 \\
& & waktu & 0.092382 \\
& & generasi & 778 \\
\hline \multirow{3}{*}{3} & Tipe 2 & f(x) & -419.726 \\
& & waktu & 0.040551 \\
& & generasi & 98 \\
\hline
\end{tabular}


Data yang digunakan adalah saham LQ45 (http://finance.yahoo.com/). Berikut adalah mean returndari 43 saham LQ45 :

\section{Tabel 4.Mean Return Saham LQ45}

\begin{tabular}{|c|c|}
\hline Saham & Mean Return \\
\hline 1 & 0.0025 \\
\hline 2 & 0.0032 \\
\hline 3 & -0.0007 \\
\hline 4 & 0.0001 \\
\hline 5 & -0.0045 \\
\hline 6 & -0.0048 \\
\hline 7 & 0.0008 \\
\hline 8 & 0.0024 \\
\hline 9 & 0.0012 \\
\hline 10 & 0.0025 \\
\hline 11 & -0.0003 \\
\hline 12 & -0.0015 \\
\hline 13 & 0.0007 \\
\hline 14 & 0.0025 \\
\hline 15 & 0.0032 \\
\hline 16 & -0.0016 \\
\hline 17 & -0.0046 \\
\hline 18 & -0.0012 \\
\hline 19 & -0.0078 \\
\hline 20 & -0.0011 \\
\hline 21 & 0.0020 \\
\hline 22 & -0.0001 \\
\hline 23 & -0.0001 \\
\hline 24 & 0.0025 \\
\hline 25 & -0.0009 \\
\hline 26 & 0.0022 \\
\hline 27 & -0.0032 \\
\hline 28 & -0.0002 \\
\hline 29 & 0.0012 \\
\hline 30 & 0.0081 \\
\hline 31 & 0.0005 \\
\hline 32 & 0.0096 \\
\hline 33 & -0.0033 \\
\hline 34 & -0.0031 \\
\hline 35 & 0.0030 \\
\hline 36 & 0.0014 \\
\hline 37 & -0.0031 \\
\hline 38 & 0.0042 \\
\hline 39 & 0.0041 \\
\hline 40 & 0.0053 \\
\hline 41 & 0.0029 \\
\hline 42 & 0.0075 \\
\hline 43 & 0.0017 \\
\hline
\end{tabular}

Untuk penyelesaian masalah optimasi portofolio digunakan PSO tipe 1, PSO tipe 2, dan PSO tipe 3 dengan pemilihan parameter $r_{1}, r_{2}, c_{1}$, dan $c_{2}$ secara random. Selanjutnya untuk menyelesaikan masalah portofolio dengan kendala ini digunakan target return 0.001 dan syarat batas minimum untuk setiap saham 0.01 . Hasil terbaik diperoleh menggunakan metode PSO tipe 2 setelah dijalankan sebanyak 25 kali dengan hasil terbaik sebagai berikut :

Tabel 5. Hasil Optimasi Portofolio dengan Kendala Sector Capitalization

\begin{tabular}{cccc}
\hline Sektor & Saham terpilih & $\boldsymbol{y}_{\boldsymbol{i}}$ & $\boldsymbol{y s}_{\boldsymbol{i}}$ \\
\hline \multirow{4}{*}{1} & BMTR & 0.0445 & \\
& JSMR & 0.0829 & 0.353 \\
& KLBF & 0.0847 & 5 \\
& SCMA & 0.0956 & \\
& TBIG & 0.0458 & \\
\hline & BBCA & 0.0326 & \\
& BBNI & 0.0649 & 0.246 \\
& BBRI & 0.0545 & 5 \\
& BBTN & 0.0260 & \\
& BMRI & 0.0685 & \\
\hline & CPIN & 0.0508 & \\
& LSIP & 0.0203 & 0.222 \\
& ICBP & 0.0895 & 2 \\
& INDF & 0.0616 & \\
\hline 5 & ANTM & 0.0440 & \multirow{2}{*}{0.116} \\
& PTBA & 0.0315 & 4 \\
\hline 5 & INCO & 0.0410 & \\
\hline V & ASRI & 0.0164 & \multirow{2}{*}{0.095} \\
Generasi & PWON & 0.0140 & 5 \\
\hline Waktu & SMRA & 0.0651 & \\
\hline & & & 0.0030 \\
& & 658.429622 detik \\
\hline
\end{tabular}

Dari tabel di atas, dapat dilihat bahwa sahamsaham yang dengan modal lebih besar memperoleh bobot yang lebih besar dan terpilih ke dalam portofolio. Artinya sahamsaham yang tergabung pada setiap sektor merupakan kombinasi saham terbaik untuk memperoleh return yang maksimal.

\section{SIMPULAN}

Pendekatan metaheuristik Particle Swarm Optimization (PSO) merupakan salah satu metode yang baik dalam menyelesaikan masalah optimasi portofolio untuk data saham yang digunakan pada penelitian ini. Waktu yang dibutuhkan untuk memperoleh hasil yang paling optimal dengan menggunakan metode PSO tidak terlalu lama.Namun, untuk memperoleh hasil yang paling optimal perlu dilakukan modifikasi pada algoritma PSO. 


\section{DAFTAR PUSTAKA}

[1] Badriyah, Jamaliatul. Optimasi Portofolio dengan Kendala Buy-in Threshold, Cardinality, dan Roundlot Menggunakan Metode Differential Evolution, Tesis. Institut Teknologi Bandung. 2014.

[2] Biggs dkk. A Global Optimization Problem in Portofolio Selection, Springer. 2007.

[3] Biggs, Michael Bartholomew. Nonlinear Optimization with Finance Aplications, Kluwer Academic Publishers. 2005.

[4] Golmakani, Hamid Reza dan Mehrshad. Constrained Portofolio Selection using Particle Swarm Optimization, Journal of Science Direct, 38, 8327-8335. 2011.

[5] Lazinica, Alexander. Particle Swarm Optimization, In-Tech. 2009.

[6] Naiborhu, Janson dkk. Particle Swarm Optimization in the Exact Linearization Technic for Output Tracking of Non-Minimum Phase Nonlinear Systems , Applied Mathematical Sciences, Vol. 7, no. 109, 5427 - 5442. 2013.

[7] Soleimani, H dkk. Markowitz-Based Portofolio Selection with Minimum Transaction Lots, Cardinality Constrains, and Regarding Sector Capitalization Using Genetic Algorithm, Journal of Science Direct, 36, 5058-5063. 2008. 